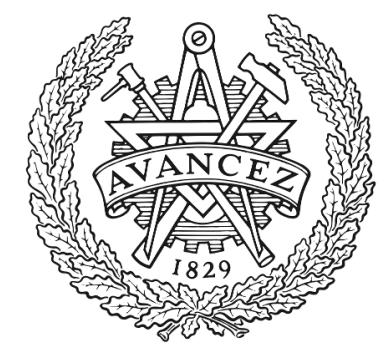

\title{
CHALMERS
}

UNIVERSITY OF TECHNOLOGY

\section{Millimeter-Wave Wideband Waveguide Power Divider with Improved Isolation between Output Ports}

Downloaded from: https://research.chalmers.se, 2023-04-26 14:31 UTC

Citation for the original published paper (version of record):

Gouda, A., López, C., Desmaris, V. et al (2021). Millimeter-Wave Wideband Waveguide Power Divider with Improved Isolation between Output Ports. IEEE Transactions on Terahertz Science and Technology, 11(4): 408-416. http://dx.doi.org/10.1109/TTHZ.2021.3078876

N.B. When citing this work, cite the original published paper.

(C2021 IEEE. Personal use of this material is permitted.

However, permission to reprint/republish this material for advertising or promotional purposes 


\title{
Millimeter-Wave Wideband Waveguide Power Divider with Improved Isolation between Output Ports
}

\author{
A. Gouda, C. López, V. Desmaris, D. Meledin, A. Pavolotsky and V. Belitsky, Senior Member, IEEE
}

\begin{abstract}
We present a novel compact wideband waveguide $\mathrm{T}$-junction power divider especially suited for $\mathrm{mm}$-wave and $\mathrm{THz}$ frequencies. It incorporates substrate-based elements into a waveguide structure to provide the output port's isolation and matching. The internal port is introduced at the apex of the Tjunction formed as E-probe on a substrate. This facilitates efficient coupling of the reflected energy from the output port to a novel thin-film based resistive termination integrated with the E-probe onto the same substrate and fabricated by means of thinfilm technology. A power divider was designed, simulated, and fabricated for the frequency band $150-220 \mathrm{GHz}$, to experimentally verify the theoretical and simulated performance. The results showed excellent agreement between the simulations and measurements with the devices demonstrating a remarkable return loss of $20 \mathrm{~dB}$ for both the input and output ports for a three-port device with equal split and isolation better than $17 \mathrm{~dB}$ between the output ports. Furthermore, the measured insertion loss is less than $0.3 \mathrm{~dB}$ and the amplitude and phase imbalance are $0.15 \mathrm{~dB}$ and $0^{\circ}$, respectively. Moreover, the divider's remarkable tolerance to the dimensions and sheet resistance of the resistive material of the built-in absorbing load, makes the device a very practical component for mm-wave and $\mathrm{THz}$ systems, in particular radio-astronomy receivers.
\end{abstract}

Index Terms - 3-dB power divider, matched ports, mm-wave, output isolation, waveguides, $T$-junction power divider.

\section{INTRODUCTION}

$\mathrm{C}$ ombining and splitting Radio Frequency (RF) signals is essential in most microwave and millimeter-wave systems. Particularly, in high power applications such as transmitters and radars, a single power amplifier often cannot reach the required $\mathrm{RF}$ power level, especially at the $\mathrm{THz}$ frequencies. Thus, the combination of the output power from more than one amplifier is required. Moreover, scientific instrumentation and space applications such as satellites and radio astronomy instrumentations strive for the most compact and ultra-low-loss components in, e.g. ultra-low noise receivers based on sideband separating mixers [1-3].

Traditional, pure substrate-based dividers commonly present excessive insertion loss at millimeter-wave frequencies, unless made of superconducting material [4]. In contrast, waveguide power divider structures have a low

The authors are with the Group for Advanced Receiver Development (GARD), Department of Space, Earth and Environment, Chalmers University of Technology, Gothenburg, Sweden insertion loss. However, waveguide-based dividers generally suffer from unmatched ports and lack of isolation. This, in turn, means that the output ports are affected by each other and any reflection from one output port will be coupled to the other output port [5]. By general microwave theory [6] - any three-port device, i.e. T-junction power divider, cannot be matched at all ports, reciprocal and lossless simultaneously, and the maximum achievable isolation and output return loss, in this case, is $6 \mathrm{~dB}[7,8]$.

In the last decades, a large number of studies have been conducted to improve the output ports' reflection and isolation to resemble Wilkinson power divider made in substrate-based strip transmission line. One of the early works by F. Takeda et al. [9] introduced a resistive slot in the septum of a waveguide T-junction divider. However, it cannot be employed for high frequencies, since the structure's dimensions become too small for fabrication at mm-wave frequencies. In $[10,11]$, a resistive septum was introduced in the waveguide divider at Ka-band and V-band, respectively, providing decent isolation and output matching. However, the resistive septum could dissipate some of the incident power resulting in extra insertion losses. A metallic strip probe was introduced via a window in the waveguide junction in $[12,13]$ to couple the reflected energy, hence, improving the performance. Moreover, a lump resistor grounded using bonding wires is used as a matched load in [12]. This solution has proven to be effective for low-frequency applications. Nevertheless, for mm-waves, the grounding wires will introduce a large parasitic inductance. Furthermore, the discrete/lumped surface mounted device (SMD) load resistor is too large and have too high parasitic to fit in the small cavities at mm-wave frequencies.

In this paper, we present a novel design approach for compact waveguide dividers for mm-wave and $\mathrm{THz}$ applications. The novel design features a combination of waveguide structure with substrate-based elements to improve the output ports' isolation and matching. The demonstration of the performance and functionality of the waveguide power divider is exemplified for prospective use in the field of millimeter-wave radio astronomy instrumentation. The frequency range employed for this demonstration corresponds to the Atacama Large Millimeter/Sub-millimeter Array (ALMA) observatory extended Band 5 receivers $[1,14]$, i.e. 150-220 GHz. 


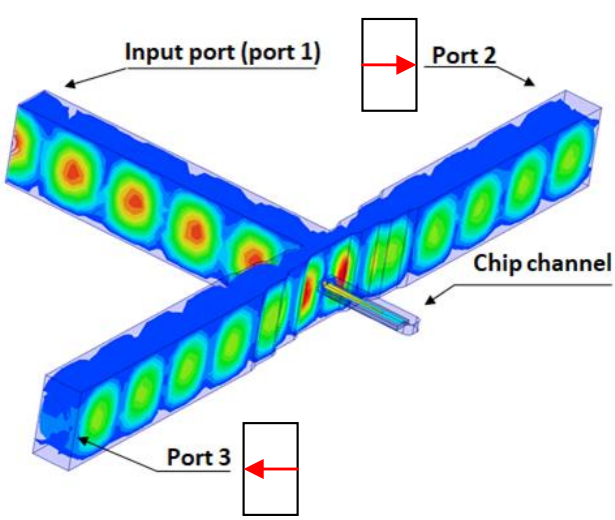

(a)

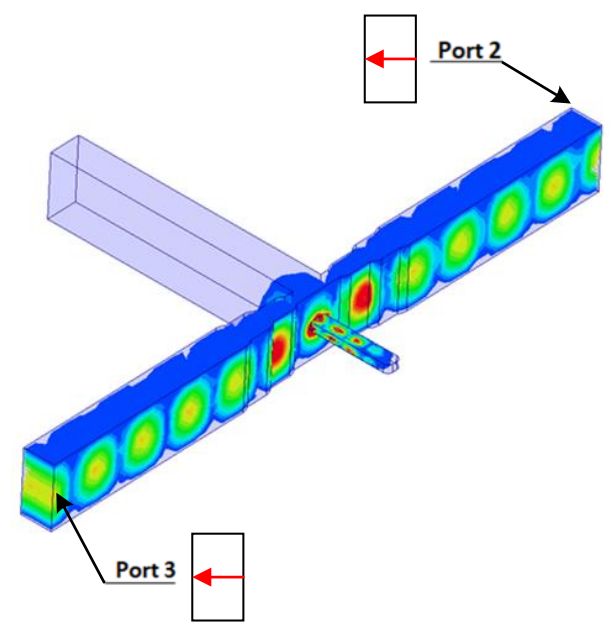

(b)

Fig. 1. E-field distribution of a) signal division when exciting port 1 or combination of signals injected in port 2 and 3 with 180 degrees phase difference and b) in-phase excitation of port 2 and 3 with signal of equal amplitude and phase. The red arrows correspond to the E-field orientation in each port.

\section{TheOry AND Design Process}

\section{A. Overall Design}

The proposed power divider design is based on the combination of a waveguide T-junction and an internal chip designed using microstrip technology, absorbing the reflected signals from the output ports. In fact, the input signal is injected into the input waveguide port and is thereafter divided into two signals, ideally with equal amplitude and a phase difference of 180 degrees, as shown in Fig. 1a, illustrating the E-field distribution in a 3D model of the divider. Noteworthy, the field propagation shows that the waveguide dominant mode does not propagate inside the chip channel as it was designed with subcritical dimensions precluding propagation in the substrate and the channel.

By the principle of reciprocity, Fig. 1a also represents the field distribution when the divider is used to combine two signals of equal amplitudes that are fed in-anti-phase from port 2 and 3. In that case, all the signals are recombined in port 1, which makes the device very suited for high power signal combination, where only an insignificant fraction of the incoming signals would be absorbed in the load in the chip

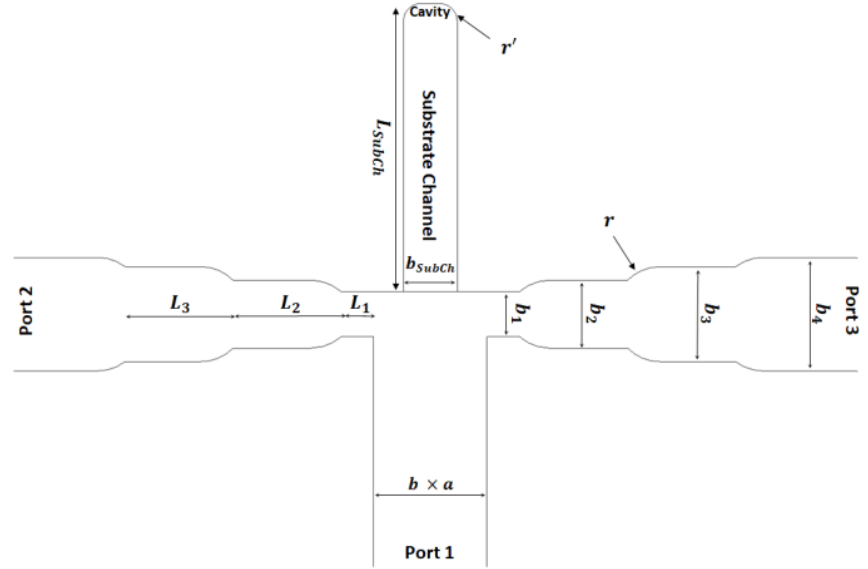

Fig. 2. Cross-section of the waveguide structure $\left(a=1.26 \mathrm{~mm}, b=b_{4}=0.63\right.$ $\mathrm{mm}, \mathrm{b}_{1}=0.25 \mathrm{~mm}, \mathrm{~L}_{1}=0.18 \mathrm{~mm}, \mathrm{~b}_{2}=0.376 \mathrm{~mm}, \mathrm{~L}_{2}=0.6 \mathrm{~mm}, \mathrm{~b}_{3}=0.527 \mathrm{~mm}$, $\mathrm{L}_{3}=0.6 \mathrm{~mm}, \mathrm{~L}_{\text {SubCh }}=1.6 \mathrm{~mm}, \mathrm{r}=0.25 \mathrm{~mm}$ and $\mathrm{r}^{\prime}=0.1 \mathrm{~mm}$ ).

channel, if the phasing of the signals differs from $180^{\circ}$. For completeness, Fig. $1 \mathrm{~b}$ shows the $\mathrm{E}$ field distribution in the structure, when port 2 and 3 are excited with two in-phase signals with equal amplitude, leading to the recombination of the signals in the built-in load and no signals exit at the main waveguide, i.e. port 1 . This behavior is consistent with the complete set of S parameters shown in [13].

\section{B. Design of the Waveguide Structure}

The waveguide structure consists of two parts; an E-plane waveguide T-junction divider, and a substrate channel where the chip absorbing reflections from the output port is mounted. For a maximum power transfer from the waveguide to the chip, the substrate should be inserted into the center of the Tjunction side wall [12].

Standard WR-5 rectangular waveguide has $a_{W R 5}$ and $b_{W R 5}$ dimensions of $1.295 \mathrm{~mm} \times 0.648 \mathrm{~mm}$ resulting in first and second mode cutoff frequencies of $115.8 \mathrm{GHz}$ and $230 \mathrm{GHz}$, respectively. However, in our design and similar to the ALMA Band 5 receivers [1], a modification on the standard WR-5 was done leaving a wider margin between the highest used frequency, i.e. $220 \mathrm{GHz}$, and the cutoff frequency of the second mode to be $240 \mathrm{GHz}$. Thus, the modified rectangular waveguide has a dimension $\mathrm{a} \times \mathrm{b}$ of $1.26 \mathrm{~mm} \times 0.63 \mathrm{~mm}$ (Fig. 2 ). Our simulations showed the waveguide size difference has a negligible effect in measurements. The impedance transformation is done using the output waveguides branches with two-section Chebyshev transformers (Fig. 2, $b_{2}$ and $b_{3}$ ) to provide the desired bandwidth. The section length $\left(L_{2}\right.$ and $L_{3}$ ) of these transformers is near a quarter-guided wavelength for each section.

In the T-junction, a septum is traditionally used to improve the performance of the input return loss $S_{11}$. However, in this design, the septum is completely removed to give space for the substrate channel, and ease fabrication. In order to preserve the input return loss performance and compensate for the septum removal as well as the probe impedance, the structure dimensions should be modified and optimized using electromagnetic simulations (Fig. 2). 


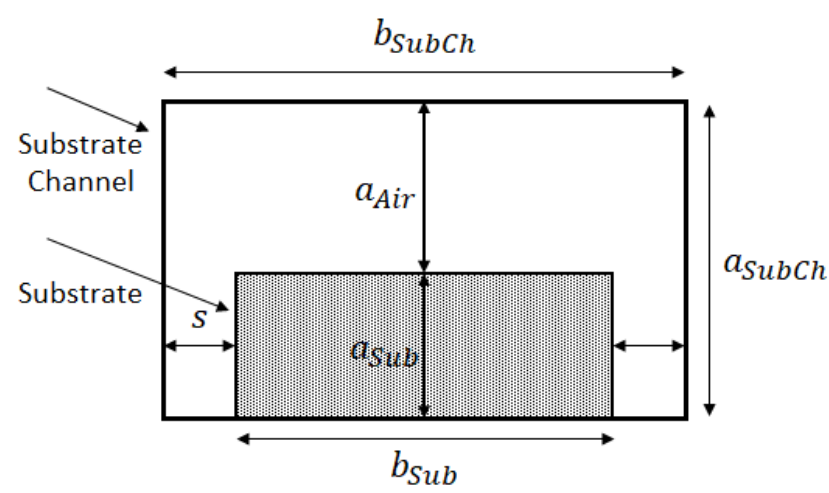

Fig. 3. Cross-section of the substrate and substrate channel $\left(b_{\mathrm{SubCh}}=300 \mu \mathrm{m}\right.$, $a_{\text {SubCh }}=162.5 \mu \mathrm{m}, b_{\mathrm{Sub}}=280 \mu \mathrm{m}, \mathrm{a}_{\mathrm{Sub}}=65 \mu \mathrm{m}, \mathrm{a}_{\mathrm{Air}}=97.5 \mu \mathrm{m}$ and $\left.\mathrm{s}=10 \mu \mathrm{m}\right)$.

As the substrate channel connects to the waveguide, it is important that the height dimension of the substrate channel $b_{\text {SubCh }}$ is designed with subcritical sizes to prevent unwanted waveguide modes to propagate inside it, this accounting for the permittivity of the substrate. The total width of the substrate channel $a_{\text {Subch }}$ depends on two values (Fig. 3): the thickness of the substrate $a_{S u b}$ and the required air region above the substrate $a_{A i r}$ as microstrip lines are patterned on the substrate. Simulations show a distance of 1.5 of the substrate thickness $\left(1.5 a_{S u b}\right)$ is enough for the field to propagate in the air region. A z-cut crystalline quartz substrate with a thickness of $65 \mu \mathrm{m}$ and dielectric constant $\epsilon_{r}$ of 4.43 was used (Fig. 3). The same type of substrate was employed in several works related to ALMA bands providing ultra-low loss performance at mm-wave and $\mathrm{THz}$ frequencies [15-18]. A gap between the substrate and the side walls of the channel is required on both sides $(s)$. This is implemented to avoid the microstrip to get short-circuit by the channel walls and for some practical reasons, e.g. dicing and mounting tolerances.

\section{Design of the Internal Chip}

To improve the output ports' isolation and return loss, the reflected energy from the output ports, i.e. ports 2 and 3, needs to be coupled to a resistive load by means of a suspended probe. A wideband E-plane probe is employed to transform the impedance of the waveguide mode of almost $400 \Omega$, into microstrip mode with real impedances rounding 30 to $60 \Omega$ [19].

A novel probe is designed (Fig. 4a) and simulated using 3D simulator HFSS [20], inspired by the work of J. W. Kooi et al. [21] on radial probes, though with a series of modifications for implementation in a T-junction configuration rather than with a back short. The radial probe itself has a real impedance of 44 $\Omega$ at the center frequency of $185 \mathrm{GHz}$, as shown on Fig $4 \mathrm{~b}$ (green line). The probe is connected to a transmission line (TL) $Z_{T L}$ of characteristic impedance $44 \Omega$ using a portion high impedance line (HI), which acts as an inductive reactance (Fig. 4a) yielding a real impedance of the overall structure over most of the band as shown in Fig. $4 \mathrm{~b}$.

The TL is later terminated using a resistive load, and this load should ideally not require a physical connection to the

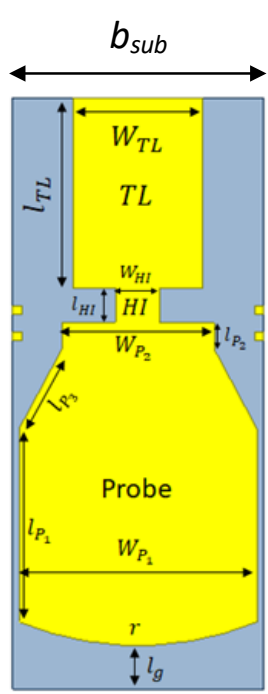

(a)

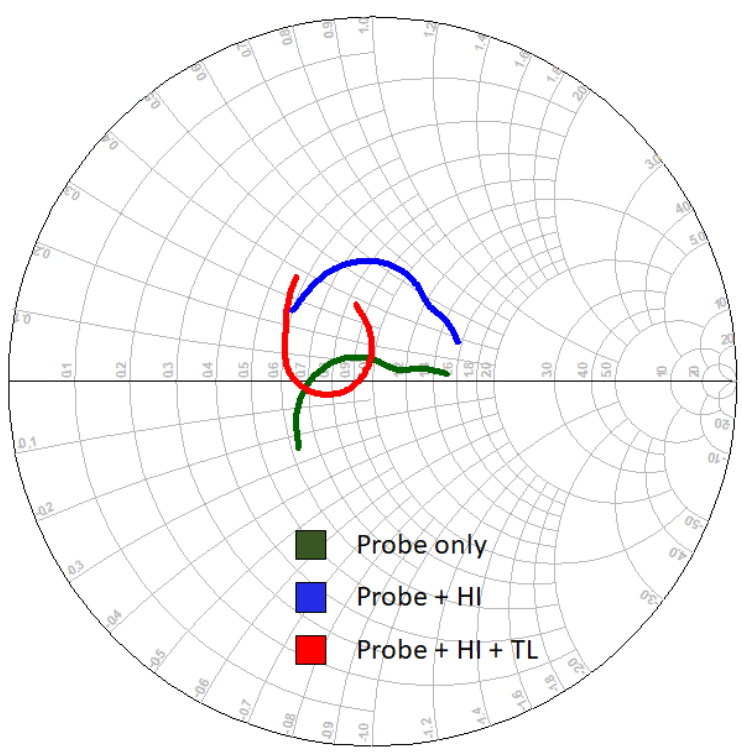

150 to $220 \mathrm{GHz}$

(b)

Fig. 4. a) Geometry of the chip design $\left(\mathrm{Z}_{\mathrm{TL}}=44 \Omega, 1_{\mathrm{TL}}=217.7 \mu \mathrm{m}, \mathrm{W}_{\mathrm{TL}}=145.2\right.$ $\mu \mathrm{m}, \mathrm{Z}_{\mathrm{HI}}=80 \Omega, \mathrm{l}_{\mathrm{HI}}=40 \mu \mathrm{m}, \mathrm{W}_{\mathrm{HI}}=50 \mu \mathrm{m}, \mathrm{l}_{\mathrm{P} 1}=221 \mu \mathrm{m}, \mathrm{W}_{\mathrm{P} 1}=266 \mu \mathrm{m}, \mathrm{l}_{\mathrm{P} 2}=30$ $\mu \mathrm{m}, \mathrm{W}_{\mathrm{P} 2}=170 \mu \mathrm{m}, \mathrm{l}_{\mathrm{P} 3}=103 \mu \mathrm{m}, \mathrm{l}_{\mathrm{g}}=50 \mu \mathrm{m}, \mathrm{r}=23^{\circ}$ and $\left.\mathrm{b}_{\text {sub }}=280 \mu \mathrm{m}\right)$, and $\mathrm{b}$ ) Corresponding input impedance of the chip in a Smith chart. The substrate has two aligning marks at the left and right from the apex of the E-probe, those facilitate the mounting of the substrate into the block.

ground. Floating loads earlier proposed by R. Monje et al. [22], are not suitable for our design since the substrate size is limited by the requirement to fit the channel's subcritical dimensions. Therefore, a novel termination is introduced, using a lossy transmission line (Fig. 5), made of resistive materials with sheet resistances in the vicinity of $30 \Omega / \mathrm{sq}$.

The final width of the lossy transmission line was 145.2 $\mu \mathrm{m}$. The complex characteristic impedance of the lossy TL $\left(Z_{\text {lossyTL }}\right)$ is close to $80-\mathrm{j} 1.4 \Omega$. Therefore, an impedance transformation is required between the conductor TL $\left(Z_{T L}=44\right.$ $\Omega)$ and the lossy TL $\left(Z_{\text {lossyTL }} \approx 80 \Omega\right)$. A 3-section Chebyshev transformer is employed denoted by their characteristic impedances $Z_{1}-Z_{4}$ (Fig. 5). Note that the resistive material is 


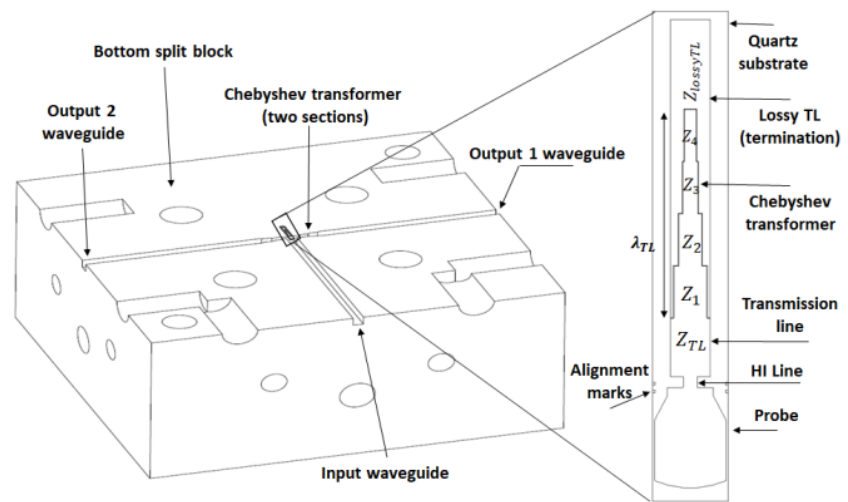

Fig. 5. Overall detailed 3D drawing of the bottom split waveguide block and the chip design with a Chebyshev 3-section transformer between the conductor TL and the lossy TL $\left(\lambda_{\mathrm{TL}}=770 \mu \mathrm{m}, \mathrm{Z}_{\mathrm{TL}}=44 \Omega, \mathrm{Z}_{1}=48.2 \Omega\right.$, $\mathrm{Z}_{2}=59.4 \Omega, \mathrm{Z}_{3}=73.2 \Omega$ and $\mathrm{Z}_{4}=\mathrm{Z}_{\text {lossy } \mathrm{TL}}=80 \Omega$ ).

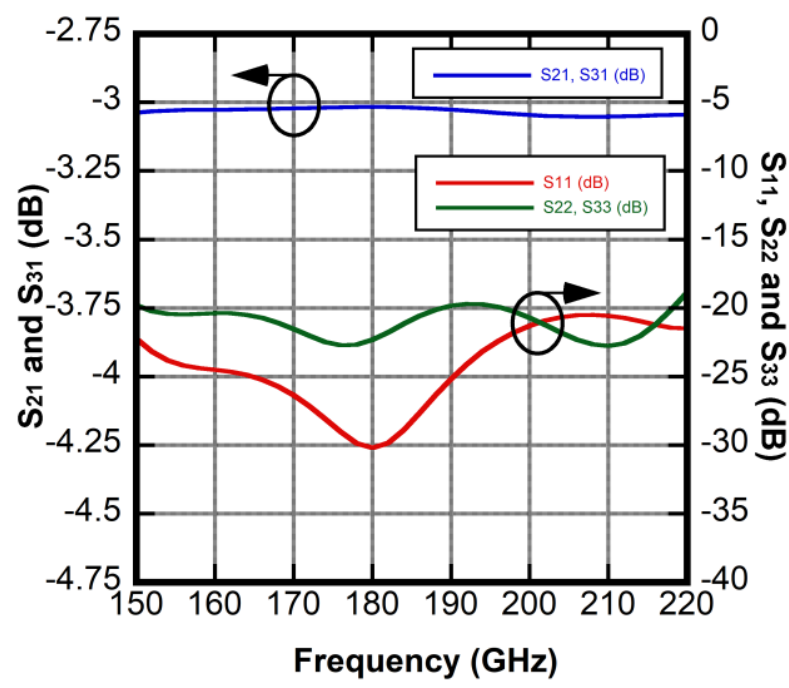

(a)

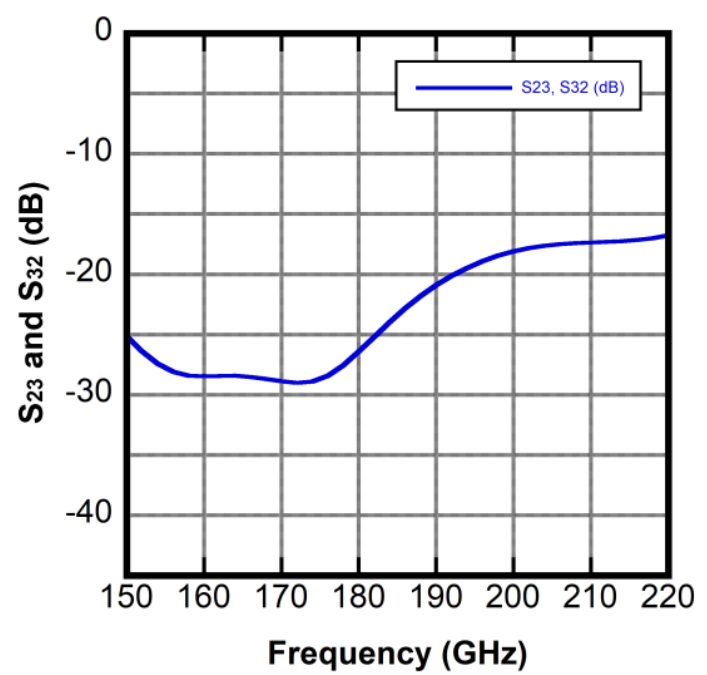

(b)

Fig. 6. Simulated a) insertion loss, input and output return loss and b) isolation, of the proposed power divider.

not present underneath the metallic Chebyshev sections, but rather the high resistivity material encloses the step transformer as it is clearly shown in Fig. 5.

\section{Simulation Results AND TOLERANCE ANALYSIS}

\section{A. Simulation Results}

The full-wave 3D simulator HFSS [20] was employed for the electromagnetic simulations. A perfect electrical conductor (PEC) boundary was used for the walls for the waveguide structure and the microstrip. The simulations show the return loss and output isolation are greater than $20 \mathrm{~dB}$ and $17 \mathrm{~dB}$ correspondingly (Fig. $6 \mathrm{a}$ and b), where the amplitude and phase imbalance are $0 \mathrm{~dB}$ and $0^{\circ}$ respectively for the entire frequency band of 150-220 GHz. Due to the perfect symmetry, it can be seen that the output return loss $\left(S_{22}\right.$ and $\left.S_{33}\right)$ and isolation $\left(S_{32}\right.$ and $\left.S_{23}\right)$ are equal and hence only one of them will be presented further in the tolerance analysis.

\section{B. Tolerance Analysis}

Due to small dimensions and possible inaccuracy in the component fabrication and assembly, a tolerance analysis was performed to assess the robustness of the design against variation of the geometrical and physical parameters of the different parts of the divider. Specifically, two different analyses were treated; the variation of sheet resistance in the resistive load from 25 to $45 \Omega / \mathrm{sq}$ and chip misalignment of $\pm 20 \mu \mathrm{m}$.

Within the investigated range of the sheet resistance of the resistive termination, the complex characteristic impedance of the resistive line remains almost constant, which means no reflection will occur with the conductor TL. This translates into a remarkable robustness of the design against variations of the sheet resistance of the termination, as shown in Fig. 7 ac, where the return loss and isolation remain well within adequate range for the device to perform, while the difference in insertion loss is hardly noticeable, as depicted by the almost overlapping insertion loss curves on Fig.7a. Furthermore, the amplitude and phase imbalance are still exactly $0 \mathrm{~dB}$ and $0^{\circ}$, respectively due to the perfect symmetry.

Mounting the chip in the right position requires quite accurate manual manipulation of the chip to place its waveguide probe in the designed location with respect to the waveguide wall. The task appears to be even more challenging due to the microscope vision parallax when observing the chip, waveguide and chip channel in the same field of view of the microscope. Therefore, chip misalignment can frequently occur in both directions, i.e. \pm , where the " $+"$ sign means that part of the high impedance line is entering the waveguide whereas the "-" sign indicates that part of the probe is located slightly inside the substrate channel. We simulated and compared the performance of the chip misaligned compared to its designed position. Since the mounting accuracy lies between $\pm 10 \mu \mathrm{m}$ and $\pm 20 \mu \mathrm{m}$, these values were simulated (Fig. $8 \mathrm{a}-\mathrm{c}$ ).

From Fig. 8, it can be concluded that the insertion loss and input return loss are very tolerant to the position of the chip. On the other hand, the output return loss and isolation (b and c) are mainly depending on the position of the chip. For instance, a misalignment of $-20 \mu \mathrm{m}$ give an acceptable isolation performance but the output return loss is degraded. 


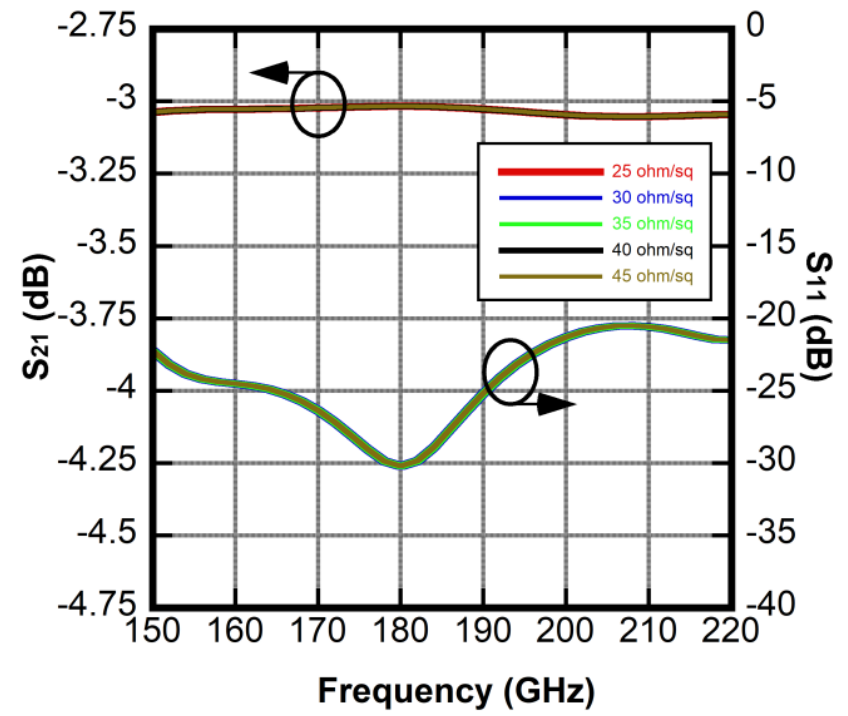

(a)

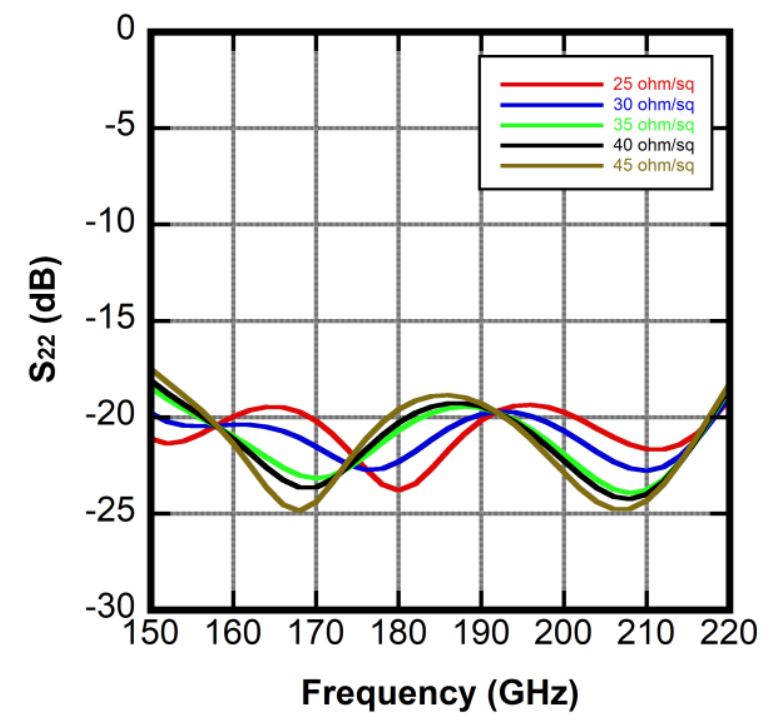

(b)

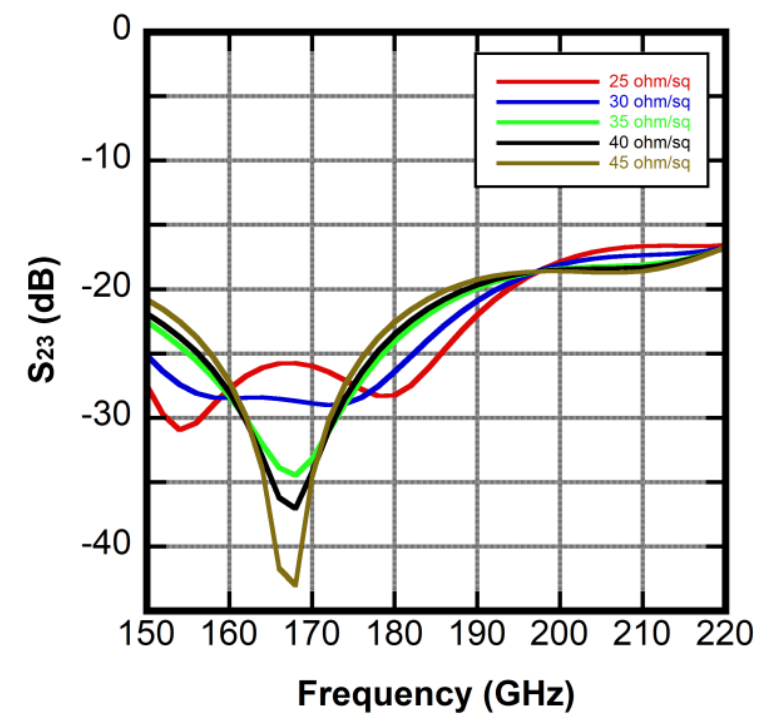

(c)

Fig. 7. Simulated a) insertion loss and input return loss, b) output return loss and c) isolation, of the divider with sheet resistance of the termination varying from $25 \Omega / s q$ to $45 \Omega / s q$.

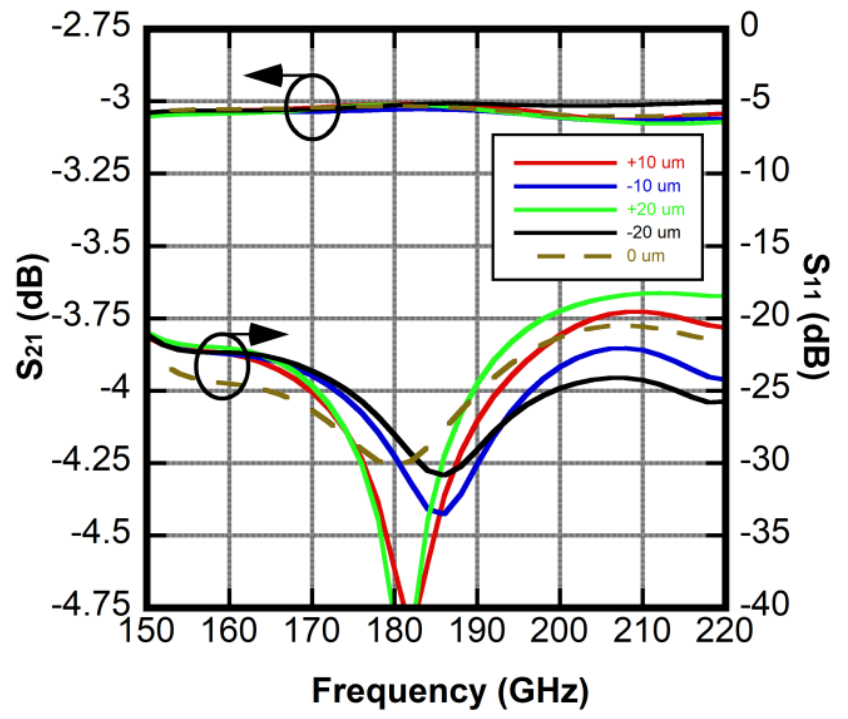

(a)

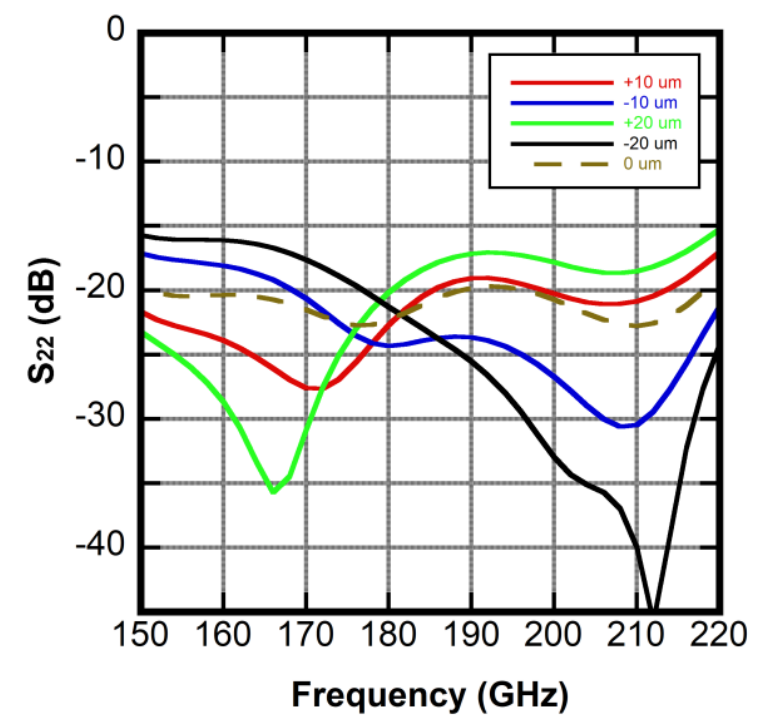

(b)

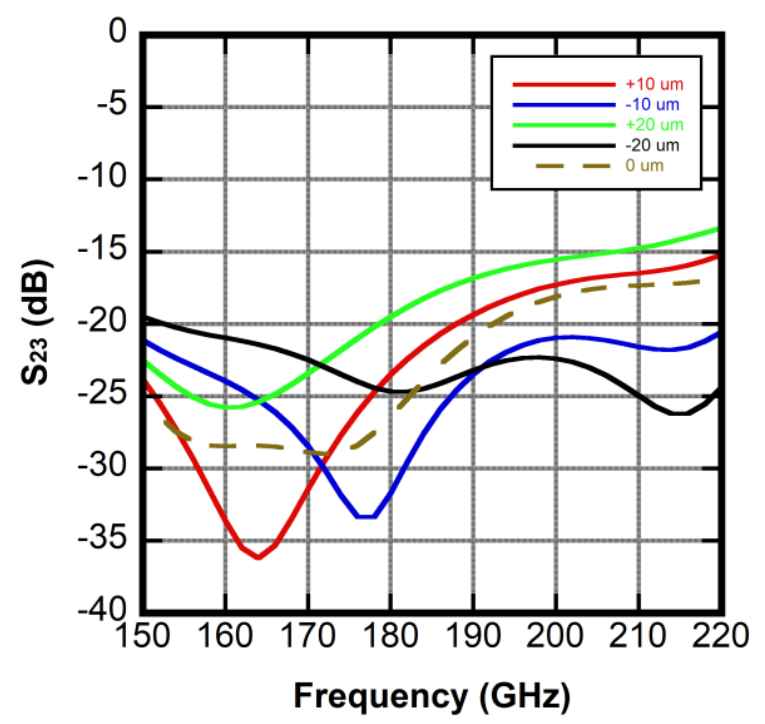

(c)

Fig. 8. Simulated a) insertion loss and input return loss, b) output return loss and c) isolation, of the divider with chip misalignment of \pm 10 and $\pm 20 \mu \mathrm{m}$. 
With the focus on having a better port matching, minor compromise on isolation could be tolerated. When the curves of Fig. 8 are inspected together, it can be noticed that a tolerance of $\pm 10 \mu \mathrm{m}$ (red and blue curves) satisfies the condition of perfectly matched ports with compromised isolation.

Furthermore, glue is used underneath the chip during the mounting process to maintain its position after assembly. It is crucial to guarantee that the glue does not affect the overall performance. Therefore, a layer of glue with a thickness of 5 $\mu \mathrm{m}$ and refractive index $n$ of 1.48 ( $\epsilon_{r}$ of 2.25) was included in the simulations and our analysis shows that the performance of the divider remained unchanged.

\section{DEVICE FABRICATION}

To validate the proposed design and simulated results, the device (waveguide and chip) is fabricated and measured.

\section{A. Waveguide Fabrication}

The design allows using a split-block technique (split in the middle of the waveguide broad wall). The three waveguides, impedance transformer, and substrate channel are milled inside $25 \mathrm{~mm} \times 25 \mathrm{~mm}$ area size split-block of a $\mathrm{TeCu}$ alloy (Fig. 9). The typical milling tolerance is $\pm 5 \mu \mathrm{m}$ and the minimum diameter of the milling tool ( $r$ and $r^{\prime}$ in Fig. 2) depends on the cut depth. As a result, a slight deviation between the simulated and fabricated waveguide dimensions may occur. The fabricated dimensions were measured using Zygo Optical 3D profiler [23] with a lateral pixel size of around $0.8 \mu \mathrm{m}$ and vertical resolution of $3 \mu \mathrm{nm}$. The lateral dimensions have been read out from the recorded 3D image with a help of Vision Pro 8.3.0 machine vision software. The simulated and fabricated dimensions are summarized in Table I, where the parameters are referred to Fig. 2.

\section{B. Chip Fabrication}

The chips are fabricated in-house using photolithography process on a $25 \mathrm{~mm} \times 25 \mathrm{~mm}$ quartz substrate $65 \mu \mathrm{m}$ thick. The Ti-N resistive material used for the fabrication of the microstrip termination is deposited by means of magnetron sputtering prior to the definition of the probe and impedance transformers using e-beam evaporation of $\mathrm{Ti} / \mathrm{Au}$ of about 20 and $600 \mathrm{~nm}$ respectively. TLM test structures are also fabricated [24] to characterize the sheet resistance of the used Ti-N and Ti/Au gold metallization. The resulting sheet resistance of Ti-N was measured to be $45 \Omega / \mathrm{sq}$, whereas the sheet resistance of the gold metallization was estimated to be $0.045 \Omega /$ sq. The diced chips were glued in the chip channel prior to closing the two halves of the split-block waveguide assembly.

\section{Measurements}

A Keysight PNA-X Vector Network Analyzer (VNA) with two VDI WR-5 frequency extenders for the range 150-220 $\mathrm{GHz}$ were employed to characterize the fabricated device. The extenders were calibrated employing a Through-Reflect-Line (TRL) calibration. In Fig. 11 a, it can be seen that the signal
TABLE I

DESIGNED AND FABRICATED DIMENSIONS OF THE BLOCK STRUCTURE

\begin{tabular}{ccc}
\hline \hline Parameter & DESIGNED VALUE $[\mathrm{mm}]$ & Fabricated value $[\mathrm{mm}]$ \\
\hline$b$ & 0.630 & 0.635 \\
$b_{1}$ & 0.250 & 0.260 \\
$b_{2}$ & 0.376 & 0.384 \\
$b_{3}$ & 0.527 & 0.580 \\
$b_{\text {SubCh }}$ & 0.300 & 0.296 \\
$a_{\text {Sub }}$ & 0.065 & 0.065 \\
$a_{\text {Air }}$ & 0.0975 & 0.098 \\
\hline \hline
\end{tabular}

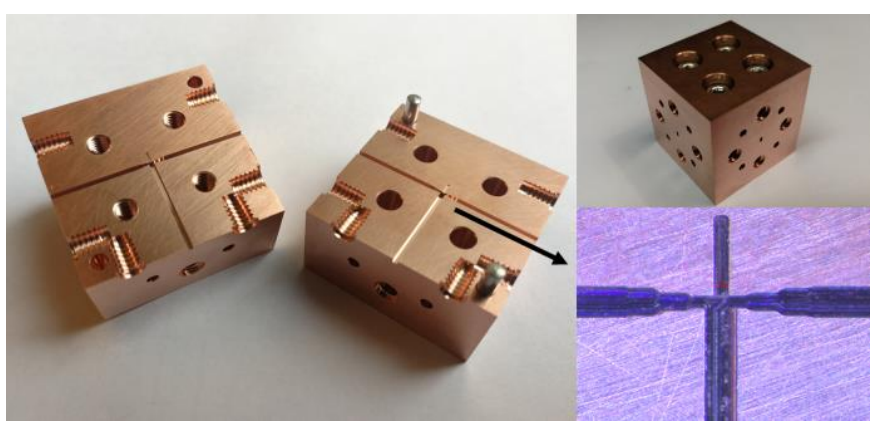

Fig. 9. Photograph on the left shows the top and bottom E-plane split-block pieces, upper right shows the assembled block and bottom-right illustrated a microscopic picture of the $\mathrm{T}$-junction, substrate channel and impedance steps. The block size is $25 \mathrm{~mm} \times 25 \mathrm{~mm} \times 25 \mathrm{~mm}$.

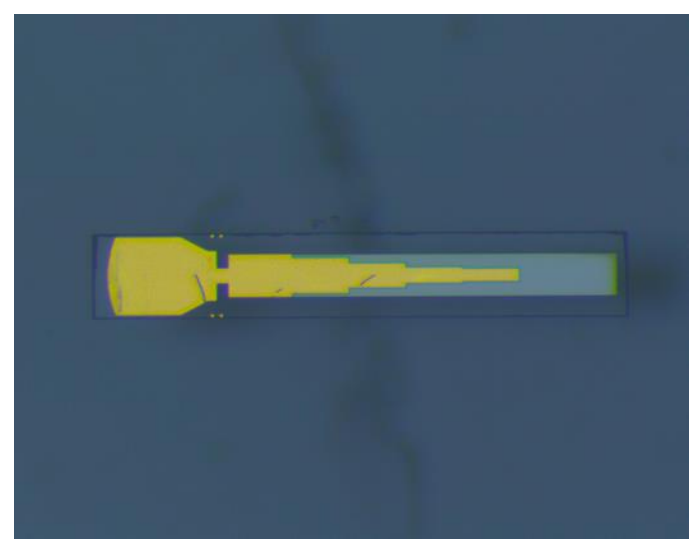

(a)

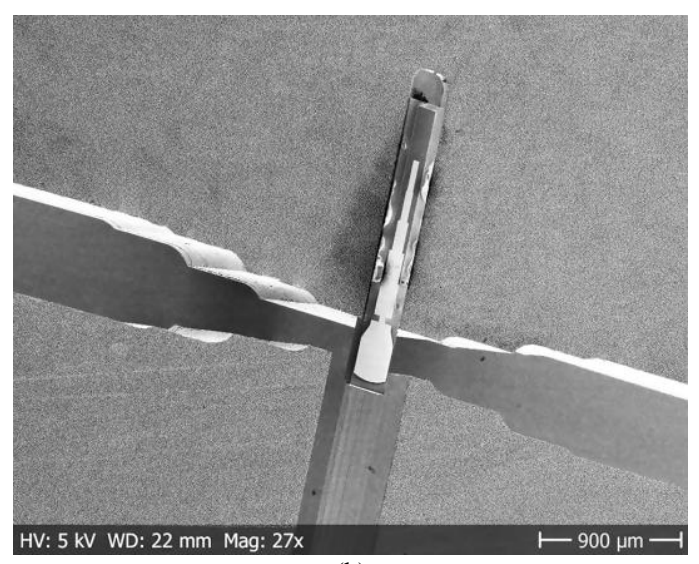

(b)

Fig. 10. a) Microscopic picture of the diced chip and b) SEM picture of the mounted chip in the substrate channel. 


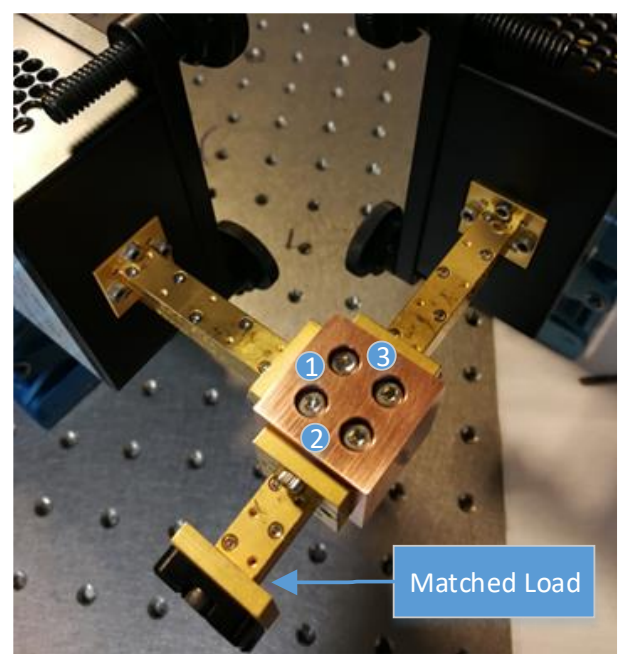

(a)

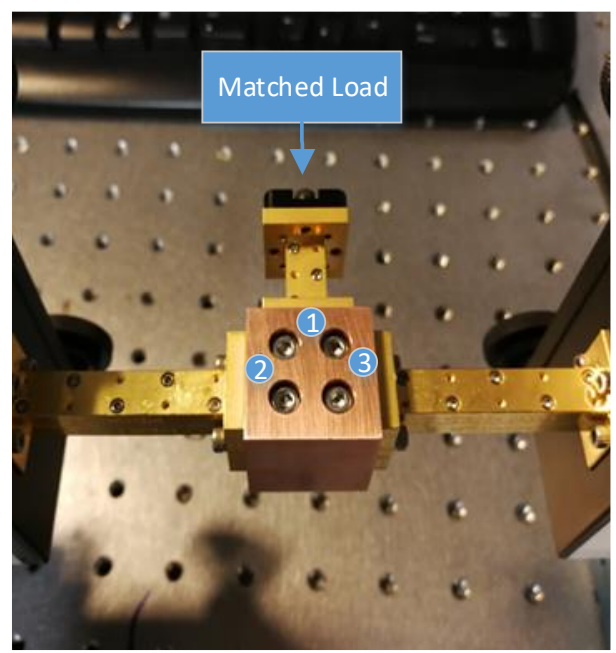

(b)

Fig. 11. Pictures of the two measurement configurations. a) Measuring the insertion loss, input return loss and transmission, and b) measuring the isolation and output return loss.

was applied at port 1 and received at the port 3 while the port 2 was terminated with a standard WR-5 waveguide matched load. This allows measuring the input return loss for port 1, and the insertion loss and output return loss for port 3 . Analogously, the insertion loss and output return loss for port 2 were obtained with port 1 and 2 connected to the extension modules and port 3 terminated. Thereafter, as depicted in Fig. $11 \mathrm{~b}$, isolation was measured by terminating port 1 and connecting port 2 and 3 to the frequency extenders.

\section{RESULTS AND DisCUSSION}

The measured performance of the fabricated structures is presented in Fig. 12 a-d and show excellent agreement with simulation results. Noteworthy, for a fair comparison, the plotted simulation results take into account the actual fabricated waveguide dimensions as the insertion loss and input return loss are sensitive to the dimensions of the waveguide structure, as well as the measured sheet resistance of the resistive films and employ copper material and surface roughness of $\sim 1 \mu \mathrm{m}$. Furthermore, the input and output waveguide were extended by $12.5 \mathrm{~mm}$, which corresponds to the distance between the actual ports of the device and the measurement flange.

The measured input and output return loss are as low as 20 $\mathrm{dB}$, and the insertion loss is approximately $3.3 \mathrm{~dB}$ for almost the entire band. The excess of $0.3 \mathrm{~dB}$ of the insertion loss ( 3 $\mathrm{dB}$ corresponding to an equal split of the signal), can reasonably be ascribed to the losses in the input and output waveguides sections $(2 \times 12.5 \mathrm{~mm})$ between the measurement flange and the actual device. This is consistent with the attenuation reported for milled tellurium copper waveguides of similar dimensions, i.e., $0.015 \mathrm{~dB} / \mathrm{mm}$ [25-28]. The measured amplitude and phase imbalance are better than $0.15 \mathrm{~dB}$ and almost $0^{\circ}$, respectively while the isolation is better than $16 \mathrm{~dB}$ for the entire band of interest.

The insignificant discrepancies found between the measured and simulated results can be explained as a combination of different factors. First, the complete set of S-parameters are not measured simultaneously and given that divider's ports are perpendicular to each other, the calibration might have been affected by the necessary rotation of the frequency extenders between the different measurements and correspondingly need to bend the cables connecting the extender modules and the VNA. Second, our measurements show that the fabrication tolerance of waveguide block was somewhat bigger than envisaged. It is important to remark that not all of the fabricated waveguide dimensions were able to be measured accurately due to the measurement tool lateral resolution, especially the length of each impedance step. Finally, the positioning of the chip. Due to the small dimensions, the exact position of the chip in the channel cannot be precisely measured, and therefore, it is very likely that the chip lies about $10 \mu \mathrm{m}$ from its optimal simulated position.

The design is based on a tradeoff between the output ports isolation and return loss, nevertheless it provides a considerable improvement in the isolation of the output ports compared to the widely used standard T-junction waveguide dividers. In fact, the isolation between the output ports improved from $6 \mathrm{~dB}$ to $16 \mathrm{~dB}$ i.e. $10 \mathrm{~dB}$ of improvement, whereas the output ports return loss has been enhanced by 14 $\mathrm{dB}$ at least, i.e. from $6 \mathrm{~dB}$ to $20 \mathrm{~dB}$ and below. This implies that the crosstalk between the circuits connected at the output ports is considerably limited, which is vital for the performance of the SIS mixers in a $2 \mathrm{SB}$ receiver for example.

Furthermore, the design presented in this paper has considerable advantages in comparison with other equal split power dividers. It is suitable for a wide range of applications in the centimeter to millimeter wavelength as it covers fractional bandwidth of almost $40 \%$ around the $185 \mathrm{GHz}$ center frequency. To the authors' knowledge, this design is the first to achieve such a remarkable fractional bandwidth and simultaneously provides good isolation between the ports. Moreover, unlike the designs in $[11,12]$, the fabrication complexity is simplified as the septum is no longer required and the capability of the power handling is increased since the termination is independent on the transmission from the input port to both output ports. 


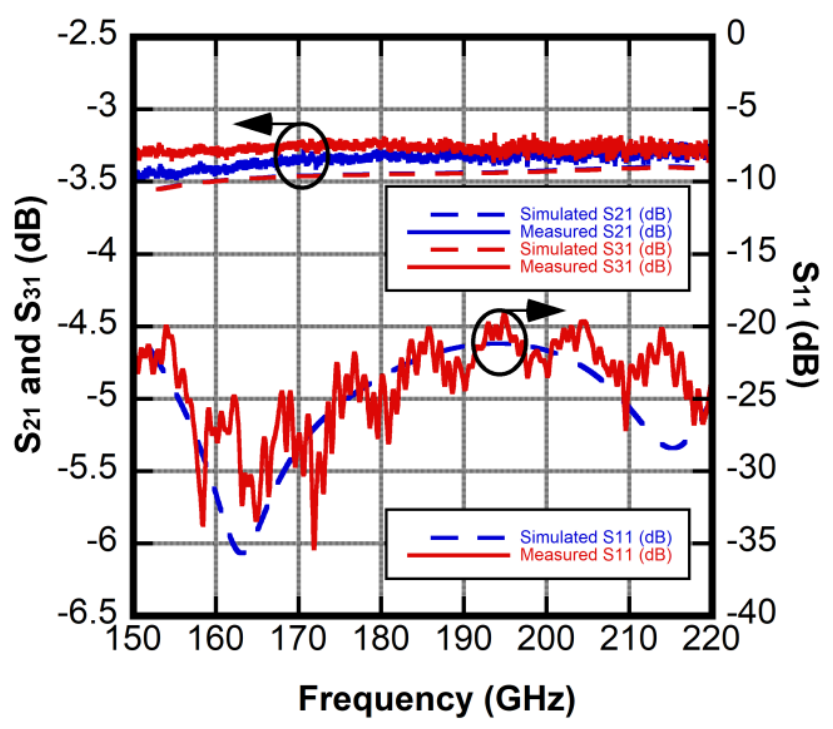

(a)

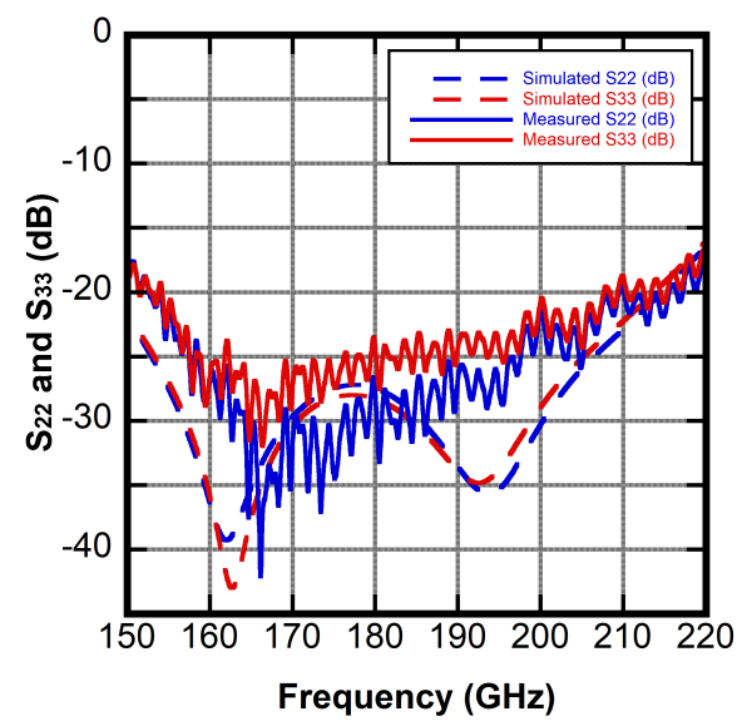

(b)

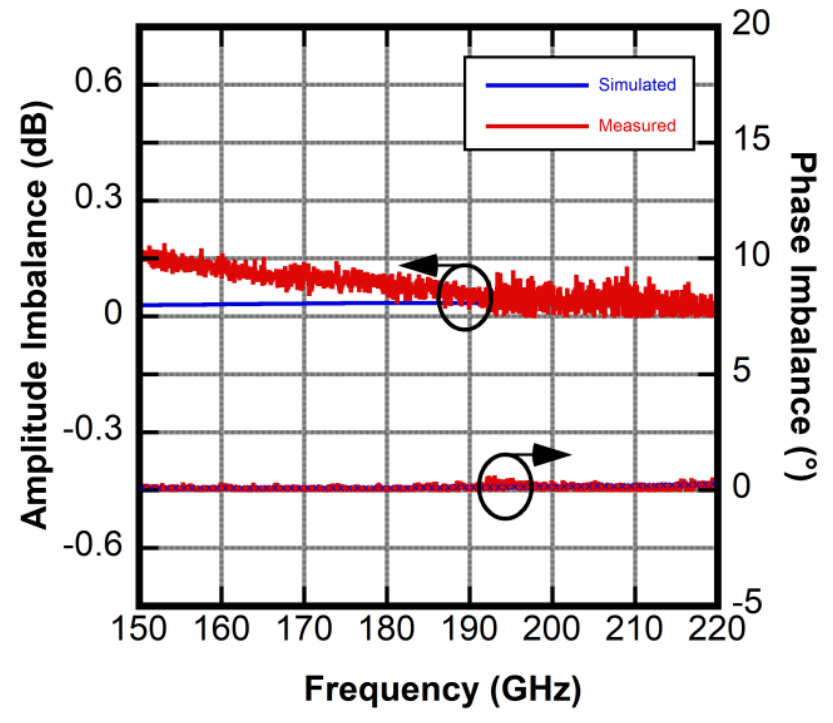

(c)

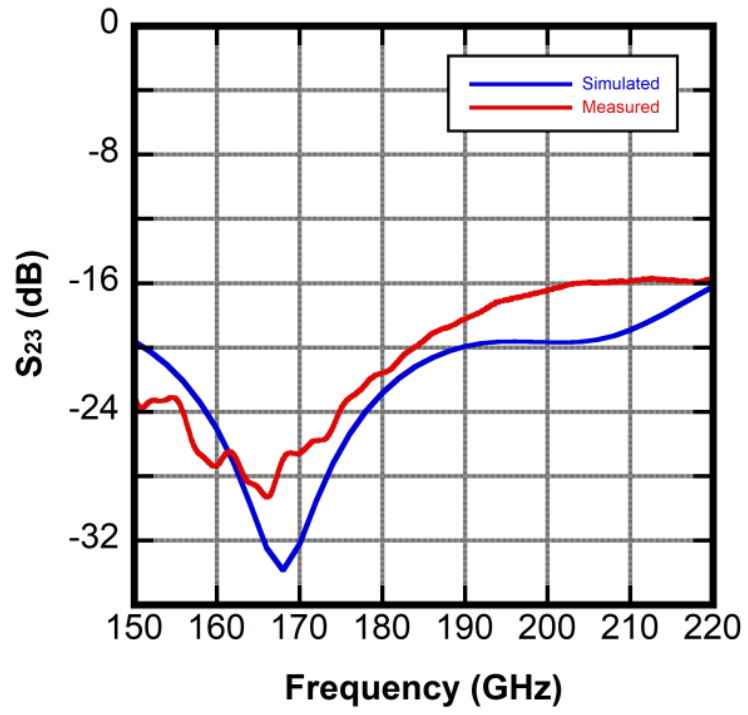

(d)

Fig. 12. Measured and simulated a) insertion loss and input return loss, b) output return loss, c) amplitude and phase imbalance and d) isolation, of the power divider.

TABLE II

COMPARISON WITH STATE-OF-THE-ART EQUAL SPLIT POWER DIVIDER

\begin{tabular}{|c|c|c|c|c|c|c|c|c|}
\hline \multirow[b]{2}{*}{ Ref. } & \multirow{2}{*}{$\begin{array}{c}\text { FBW } \\
{[\%]}\end{array}$} & \multirow{2}{*}{$\begin{array}{c}f_{c} \\
{[G H z]}\end{array}$} & \multirow{2}{*}{$\begin{array}{l}\mathrm{IL}^{*} \\
{[\mathrm{~dB}]}\end{array}$} & \multicolumn{2}{|c|}{$\mathrm{RL}^{* *}[\mathrm{~dB}]$} & \multirow{2}{*}{$\begin{array}{l}\mathrm{I} * * * \\
{[\mathrm{~dB}]}\end{array}$} & \multicolumn{2}{|c|}{ Imbalance } \\
\hline & & & & In & Out & & $\begin{array}{l}\text { Amp } \\
{[\mathrm{dB}]}\end{array}$ & $\begin{array}{c}\text { Phase } \\
{\left[{ }^{\circ}\right]} \\
\end{array}$ \\
\hline [7] & 30 & 100 & 0.3 & NA & 6 & 6 & 0.3 & $\sim \mathbf{0}$ \\
\hline [8] & 4.4 & 93 & 0.5 & 15 & 6 & 6 & 0.12 & 1.38 \\
\hline$[10]$ & 23 & 34 & 0.2 & 20 & 20 & 20 & NA & NA \\
\hline$[11]$ & 18 & 55 & 0.4 & 16 & 13 & 20 & 0.19 & 1.4 \\
\hline$[12]$ & 20 & 30 & 0.2 & 17 & 17 & 20 & 0.06 & NA \\
\hline $\begin{array}{c}\text { This } \\
\text { Work }\end{array}$ & 38 & 185 & 0.3 & $\sim 20$ & $\sim 20$ & 16 & 0.15 & $\sim 0$ \\
\hline
\end{tabular}

FBW: Fractional Bandwidth $f_{c}$ : Center frequency NA: Not Available *IL: Insertion loss **RL: Return loss *** I: Isolation

Table II compares and summarizes the performance of the proposed design with state-of-the-art equal power dividers.

\section{CONCLUSION}

In this paper, the design, fabrication, and measurement of a novel compact $3 \mathrm{~dB}$ wideband waveguide power divider operating in the $150-220 \mathrm{GHz}$ band have been presented. The proposed divider uses a combination of substrate-based and waveguide structures to overcome the excessive insertion loss of the pure substrate-based components as well as the unmatched non-isolated output ports resulting from any threeport device, e.g. a waveguide T-junction. The proposed waveguide power divider provides a $10 \mathrm{~dB}$ improved isolation between the output ports $\mathrm{T}$-junction, while keeping the return loss as low as $20 \mathrm{~dB}$ at each port. Additionally, the excess insertion loss is limited to $0.3 \mathrm{~dB}$ over the whole $150-220 \mathrm{GHz}$ band. The unique electrical performance, compactness of the divider and its remarkable tolerance to the dimensions and sheet resistance of the resistive material of the built-in absorbing load, makes the device a very practical component for $\mathrm{mm}$-wave and $\mathrm{THz}$ systems, in particular radio-astronomy receivers. 


\section{ACKNOWLEDGMENT}

The authors would like to thank Sven-Erik Ferm and Mathias Fredrixon for their support and fabrication of the waveguide parts.

\section{REFERENCES}

[1] Belitsky, V., Bylund, M., Desmaris, V. et al (2018), ALMA Band 5 receiver cartridge: Design, performance, and commissioning. Astronomy and Astrophysics, 611, http://dx.doi.org/10.1051/0004-6361/201731883.

[2] Belitsky, V., Lapkin, I., Vassilev, V. et al. Facility heterodyne receiver for the atacama pathfinder experiment telescope. 32nd International Conference on Infrared and Millimeter Waves and the 15 th International Conference on Terahertz Electronics, 326-328 (2007).

[3] Belitsky, V., Lapkin, I., Fredrixon, M. et al (2018), SEPIA - A new single pixel receiver at the APEX telescope. Astronomy and Astrophysics, 612, http://dx.doi.org/10.1051/0004-6361/201731458.

[4] H. Rashid, S. Krause, D. Meledin, V. Desmaris, A. Pavolotsky and V. Belitsky, "Frequency Multiplier Based on Distributed Superconducting Tunnel Junctions: Theory, Design, and Characterization," in IEEE Transactions on Terahertz Science and Technology, vol. 6, no. 5, pp. 724-736, Sept. 2016, doi: 10.1109/TTHZ.2016.2583201.

[5] V. Vassilev et al., "Design and Characterization of a $211-275 \mathrm{GHz}$ Sideband Separating Mixer for the APEX Telescope," in IEEE Microwave and Wireless Components Letters, vol. 18, no. 1, pp. 58-60, Jan. 2008, doi: 10.1109/LMWC.2007.912026.

[6] Pozar, David M., and David M Pozar. Microwave Engineering, Wiley, 2012.

[7] V. Vassilev, V. Belitsky, D. Urbain and S. Kovtonyuk, "A new 3-dB power divider for millimeter-wavelengths," in IEEE Microwave and Wireless Components Letters, vol. 11, no. 1, pp. 30-32, Jan. 2001, doi: $10.1109 / 7260.905959$

[8] Ma Rui, Luo Mengjia, Sun Houjun, Li Zhen and Zheng Pei, "Design and simulation of a W-band two-way power divider based on substrate integrated waveguide," 2013 IEEE International Conference On Microwave Technology \& Computational Electromagnetics, Qingdao, 2013, pp. 100-102, doi: 10.1109/ICMTCE.2013.6812399.

[9] F. Takeda, O. lshida and Y. Isoda, "Waveguide Power Divider Using Metallic Septum with Resistive Coupling Slot," 1982 IEEE MTT-S International Microwave Symposium Digest, Dallas, TX, USA, 1982, pp. 527-528, doi: 10.1109/MWSYM.1982.1130780.

[10] Y. Liu, D. Niu and E. S. Li, "Three-port E-plane bifurcated waveguide power divider at millimeter-wave frequencies," 2012 Asia Pacific Microwave Conference Proceedings, Kaohsiung, 2012, pp. 998-100, doi: 10.1109/APMC.2012.6421804.

[11] Hua Zhang, Deng Yun Shao, Sheng Zeng. A Broadband MillimeterWave Waveguide Power Divider with High Isolation. American Journal of Physics and Applications. Vol. 7, No. 4, 2019, pp. 101-108. doi: 10.11648/j.ajpa.20190704.12

[12] Z. Xu, J. Xu, Y. Cui and C. Qian, "A Novel Rectangular Waveguide TJunction for Power Combining Application," in IEEE Microwave and Wireless Components Letters, vol. 25, no. 8, pp. 529-531, Aug. 2015, doi: 10.1109/LMWC.2015.2440775

[13] W. Lei, L. Li-hao and Y. Zhi-guo, "A novel power splitter based on the waveguide E-type T junction," Proceedings of 2012 5th Global Symposium on Millimeter-Waves, 2012, pp. 217-219, doi: 10.1109/GSMM.2012.6314039.

[14] [Online]. Available: www.almaobservatory.org.

[15] Risacher, C., Belitsky, V., Vassilev, V. et al. A 275-370 GHz Receiver Employing Novel Probe Structure. Int J Infrared Milli Waves 26, $867-$ 879 (2005). https://doi.org/10.1007/s10762-005-5659-0.

[16] Monje, Raquel \& Belitsky, Victor \& Vassilev, Vessen \& Pavolotsky, Alexey \& Lapkin, I. \& Desmaris, V. \& Meledin, D. \& Henke, D. \& Dochev, D.. (2008). A $0.5 \mathrm{THz}$ sideband separation SIS mixer for APEX telescope.

[17] R. Monje, V. Belitsky and V. Vassilev, "A Novel Design of Broadband Waveguide Directional Couplers and 3-dB Hybrids," 2006 IEEE MTT-S International Microwave Symposium Digest, San Francisco, CA, 2006, pp. 1169-1172, doi: 10.1109/MWSYM.2006.249399.

[18] A. M. Baryshev, R. Hesper, F. P. Mena, T. M. Klapwijk, T. A.vanKempen, M. R. Hogerheijde, B. D. Jackson, J. Adema, G. J. Gerlofsma,M. E. Bekema, J. Barkhof, L. H. R. de Haan-Stijkel, M. van den Bemt,A. Koops, K. Keizer, C. Pieters, J. Koops van het Jagt, H. H.
A.Scha-effer, T. Zijlstra, M. Kroug, C. F. J. Lodewijk, K. Wielinga,W. Boland,M. W. M. de Graauw, E. F. van Dishoeck, H. Jager, and W Wild, "The alma band 9 receiver - design, construction, characterization, and firstlight,"A\&A, vol. 577, p. A129, may 2015.

[19] C. Risacher, V. Vassilev, A. Pavolotsky and V. Belitsky, "Waveguideto-microstrip transition with integrated bias-T," in IEEE Microwave and Wireless Components Letters, vol. 13, no. 7, pp. 262-264, July 2003, doi: 10.1109/LMWC.2003.815182.

[20] HFSS High Frequency Structure Simulator Version 19.5, Agilent Technologies.

[21] J. Kooi, G. Chattopadhyay, S. Withington and et al., "A Full-Height Waveguide To Thin-Film Microstrip Transistion With Exceptional Rf Bandwidth And Coupling Efficiency," International Journal of Infrared and Millimeter Waves, vol. 24, p. 261-284, (2003).

[22] R. R. Monje, V. Vassilev, A. Pavolotsky and V. Belitsky, "High quality microstrip termination for MMIC and millimeter-wave applications," IEEE MTT-S International Microwave Symposium Digest, 2005., Long Beach, CA, 2005, pp. 4 pp.-, doi: 10.1109/MWSYM.2005.1517082.

[23] ZeGage - 0120, Optical 3D Profiler, produced by Zygo Corporation.

[24] G. K. Reeves and H. B. Harrison, "Obtaining the specific contact resistance from transmission line model measurements," in IEEE Electron Device Letters, vol. 3, no. 5, pp. 111-113, May 1982, doi: 10.1109/EDL.1982.25502.

[25] H. Rashid, D. Meledin, V. Desmaris and V. Belitsky, "Novel Waveguide 3 dB Hybrid With Improved Amplitude Imbalance," in IEEE Microwave and Wireless Components Letters, vol. 24, no. 4, pp. 212-214, April 2014, doi: 10.1109/LMWC.2013.2293671.

[26] V. Desmaris, D. Meledin, D. Dochev, A. Pavolotsky and V. Belitsky, "Terahertz components packaging using integrated waveguide technology," 2011 IEEE MTT-S International Microwave Workshop Series on Millimeter Wave Integration Technologies, Sitges, 2011, pp. 81-84, doi: 10.1109/IMWS3.2011.6061893.

[27] H. Rashid, V. Desmaris, V. Belitsky, M. Ruf, T. Bednorz and A. Henkel, "Design of Wideband Waveguide Hybrid With Ultra-Low Amplitude Imbalance," in IEEE Transactions on Terahertz Science and Technology, vol. 6, no. 1, pp. 83-90, Jan. 2016, doi: 10.1109/TTHZ.2015.2502070.

[28] C. Lopez, V. Desmaris, D. Meledin, A. Pavolotsky and V. Belitsky, "Design and Implementation of a Compact $90^{\circ}$ Waveguide Twist With Machining Tolerant Layout", in IEEE Microwave and Wireless Component Letters, vol. 30, no. 8, pp. 741-744, 2020

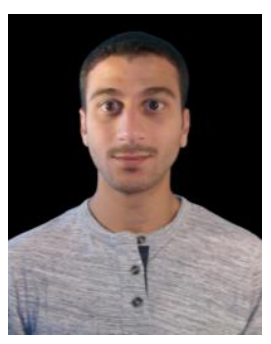

Ahmed Gouda was born in Gothenburg, Sweden, in 1993. He received the B.S. degree in electronics and communication engineering from Misr University of Science and Technology, Cairo, Egypt, in 2016, and the M.Sc. degree in Wireless, Photonics and Space engineering from Chalmers University of Technology, Gothenburg, Sweden, in 2020. He is currently working as an antenna and microwave consultant designer at Ericsson Sweden.

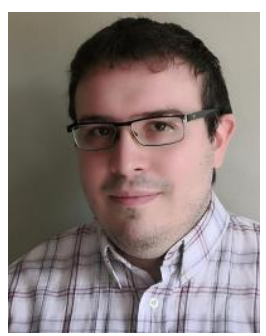

Cristian Lopez was born in Buenos Aires, Argentina, in 1990. He received the B.S. degree in electronic engineering from Facultad de Ingeniería del Ejército Grl. Div. Manuel N. Savio, Buenos Aires, Argentina, in 2012, and the M.Sc. degree in microelectronics from Universidad Politecnica de Cataluña, Barcelona, Spain, in 2018.

$\mathrm{He}$ is currently working toward the Ph.D. degree at Chalmers University of Technology, Gothenburg, Sweden.

His current research interests are the design and characterization of cryogenic components for $\mathrm{THz}$ systems. 


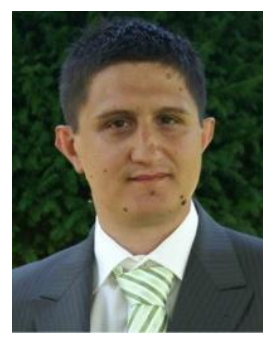

Vincent Desmaris received the M.Sc. degree in material science from the National Institute of Applied Science, Lyon, France, in 1999, and the Ph.D. degree in electrical engineering from the Chalmers University of Technology, Gothenburg, Sweden, in 2006. His thesis concerned the fabrication, characterization, and modeling of AlGaN/GaN microwave transistors. Since 2006, he has been with the Group for Advanced Receiver Development, Chalmers University of Technology. His research interests include the area of terahertz receiver technology, especially microfabrication and characterization of waveguide components and circuits, and planar cryogenic microwave devices.

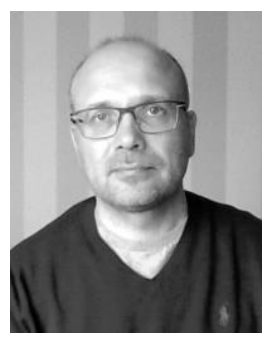

Denis Meledin received Ph.D. degree in radiophysics from MSPU, Moscow, Russia, 2003. From 2000 to 2003, he was a predoctoral fellow with Submillimeter Receiver Lab at Smithsonian Astrophysical Observatory, Cambridge, USA. Since 2003 he has been with Group for Advanced Receiver Development (GARD), Chalmers University of Technology, Gothenburg, Sweden. His work is related to development of instruments for radio-telescopes (e.g. for ALMA, APEX ). He focusses on design, development and characterization of components for radioastronomy receivers operating at microwave and $\mathrm{mm} / \mathrm{submm}$ wavelengths. Besides that, he is involved in teaching of B.S and M.S. courses, and has been a co-supervisor of a number of Ph.D. students.

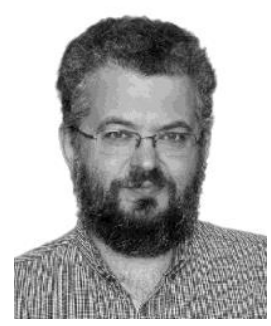

Alexey B. Pavolotsky received the M.S. and Ph.D. degrees from Moscow Aircraft Technology Institute / Technical University, in 1990 and 2003, both in material science and engineering.

Since 2002, he is with GARD, Group for Advanced Receiver Development, Onsala Space Observatory, Chalmers University of Technology, Gothenburg, Sweden. He currently holds a Senior Researcher position. His research interests include Low-Tc superconducting thin film processing and characterization, as well as microfabrication in general.

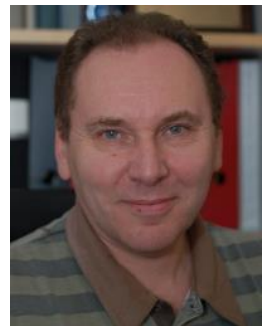

Victor Belitsky (M'95-SM'07) received the M.Sc. degree in electrical engineering from the Moscow Telecommunication Institute, Moscow, Russia, in 1977, and the Ph.D. degree in experimental physics from the Institute of Radio Engineering and Electronics, U.S.S.R. Academy of Sciences, Moscow, Russia, in 1990. He is currently a Professor and Head of the Group for Advanced Receiver Development, Department of Space, Earth, and Environmental Sciences, Chalmers University of Technology, Gothenburg, Sweden. His research interests include terahertz and superconducting electronics and components, instrumentation for radio astronomy, and environmental science. 